\title{
Surgical management of a complicated case of benign cementoblastoma impeding normal occlusion : A case report
}

\section{Case Report}

\author{
Wael Alaaeldin Hussein
}

Department of Oral and Maxillofacial Surgery, Misr International University

\begin{abstract}
True Cementoma or benign Cementoblstoma is a rare odontogenic tumor that represents less than $1 \%$ of all reported odontogenic tumors. it was first described as a benign tumour that forms cementum or cementum like tissue mass around the teeth roots and that the only true cemental neoplasms are benign cementoblastoma and cementifying fibroma.Its most common site is the posterior mandible mostly associated with molar and premolar teeth, and it rarely occurs in anterior teeth. It has a higher prevalence in male population and usually occurs before the third decade of life. the literature highlights that the treatment of choice for benign cementoblastoma is surgical removal of both the tumor and associated teeth.

In this case report, a case of a 29-year-old male patient with a benign cementoblastoma (true cementoma) in the posterior mandible impeding the path of normal occlusion is presented. Whereby surgical removal of the mass and its histological examination was done to confirm its nature. Although it is a rare neoplasm constituting to less than $1 \%$ of benign odontogenic neoplasms, oral and maxillofacial surgeons should be aware of its diagnosis, clinical picture, histopathological features, treatment and prognosis as it may pose a risk to the patient's dentition and bony structures.
\end{abstract}

Key Words: Benign cementoblastoma, case report, mandibular neoplasm, odontogenic tumors, true cementoma.

Received: 01 November 2018, Accepted: 07 April 2019

Corresponding Author: Wael Alaaeldin Hussein, Department of Oral and Maxillofacial Surgery, Misr International University, Tel.: 01101140008, E-mail: wael.alaa@miuegypt.edu.eg

ISSN: 2090-097X, January 2019, Vol. 10, No. 1

\section{INTRODUCTION}

Norberg (1930) first described the benign cementoblastoma as a benign tumour that forms cementum or cementum like tissue mass around the teeth roots ${ }^{[1]}$. The WHO (World Health Organization) in 1993 stated that the only true cemental neoplasms are benign cementoblastoma and cementifying fibroma ${ }^{[2]}$. Later the WHO classified the benign cementoblastoma as an odontogenic mesenchymal (ectomesenchymal) tumor ${ }^{[3]}$.

True Cementoma or benign Cementoblstoma is a rare odontogenic tumor that represents less than $1 \%$ of all reported odontogenic tumors. Its most common site is the posterior mandible mostly associated with molar and premolar teeth, and it rarely occurs in anterior teeth ${ }^{[2,4-6]}$. It has a higher prevalence in male population and usually occurs before the third decade of life ${ }^{[7]}$.

Benign cementoblastoma is a slowly growing ${ }^{[6-8]}$. painless lesions, although it was reported that it may be symptomatic and swelling may occur in some cases $^{[5-7,10-15]}$. Radiographically, it appears as a welldefined radiopaque mass related to the vital tooth root and is surrounded by a thin radiolucent $\operatorname{rim}^{[3,6-9,13,16-18]}$. Histopathological examination of benign cementoblastoma reports proliferating plump cells resembling cementoblasts. These cementobalsts are embeded in variable amounts of esoniphillic matrix (cementoid), which shows patchy calcifications in many areas forming cellular cementum $^{[9,16,17]}$. To reach final diagnosis clinical, histopathological and radiological findings must be thoroughly reviewed to exclude osteoblastoma, osteosarcoma andfocal sclerosing osteomyelitis ${ }^{[6,15]}$.

Brannon et. al. (2002) mentioned that the treatment of choice for benign cementoblastoma is surgical removal of both the tumor and associated teeth ${ }^{[10]}$.

\section{CASE REPORT}

A 29-year-old male was presented to Misr International University dental clinic complex with a painless intraoral mild swelling related to the mandibular second right molar. The soft tissue was of normal condition and tooth was vital, however in a tilted position causing malocclusion.

Tooth vitality was confirmed using electric pulp testing. Oral examination revealed good oral health and 
hygiene with exception to mesial shifting of lower right second molar and malposition of lower right third molar. Radiographic findings showed radio-opaque mass with a diameter of $5 \mathrm{~mm} \times 5 \mathrm{~mm}$ surrounding the root of second mandibular molar. Cone beam Computed Tomography (CBCT) showed the radiopaque mass to obliterate the anatomy of the root and was surrounded by a uniform radiolucent halo. (Figure 1, 2).

The patient was scheduled for surgery under local anesthesia to remove both right mandibular second molar with associated mass and third molar (Figure 3). The patient approved the proposed treatment plan and signed an informed consent.

Incision was done using a Bard Parker Blade \#15 and a Pyramidal full thickness flap was reflected buccally using mucoperiosteal elevator and the flap was

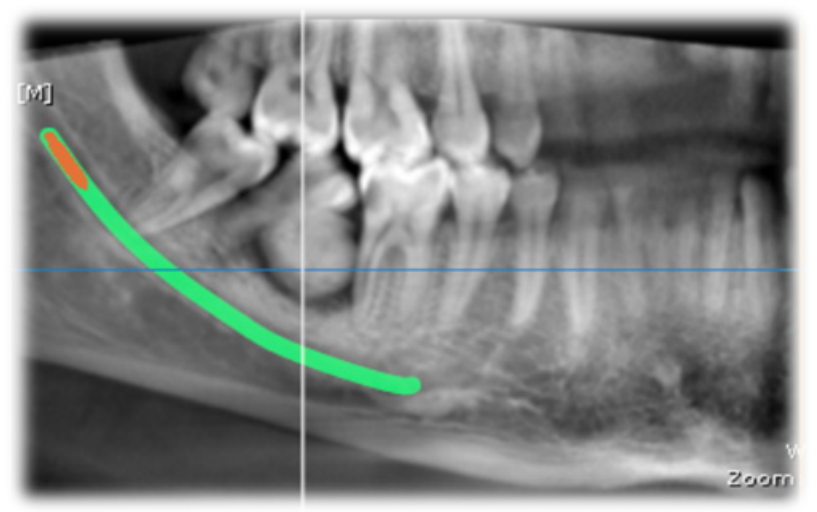

Fig. 1: Panoramic View of CBCT showing radio-opaque mass surrounded by radiolucent halo related to mandibular right second molar

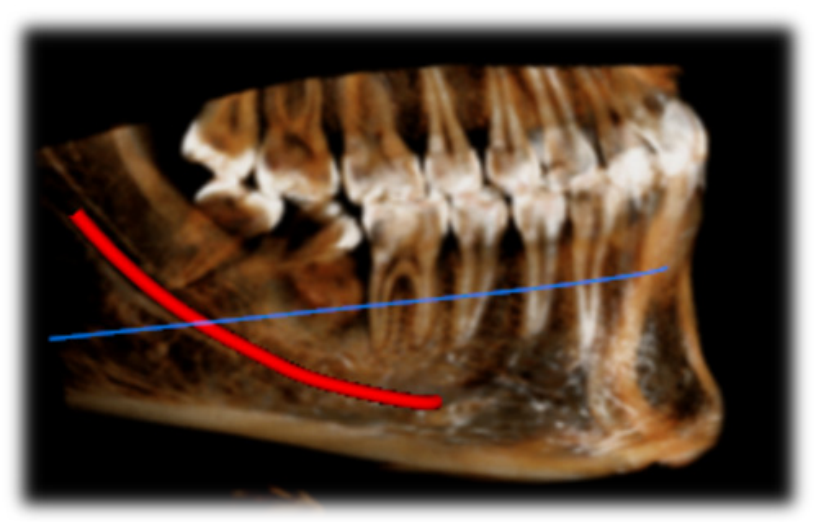

Fig. 2: 3-D reconstruction view of $\mathrm{CBCT}$ showing lesion obliturating mesial root of mandibular right second molar. retracted using Minnesota retractor (Figure 4). The third mandibular molar was first removed using mandibular forceps (Figure 5), then the second molar was luxated first then delivered buccally with the associated lesion using mandibular forceps (Figure 6). Thorough and extensive curettage and debridement of the second molar's bony socket was preformed (Figure 7). The wound was closed primarily using 3-0 silk suture (Figure 8). The lesion with associated tooth (second molar) and third molar (Figure $9 \mathrm{a}, \mathrm{b}, \mathrm{c}$ ) were sent for histopathological evaluation to MIU histopathological research lab.

Patient was given postoperative antibiotics for 5 days (Amoxillin 1g - twice daily), an analgesic for pain control (Ibubrufen $600 \mathrm{mg}$ - three times daily) for 3 days when needed, and intramuscular corticosteroids (Dexamethasone 4mg IM) for their antiedematous effect.

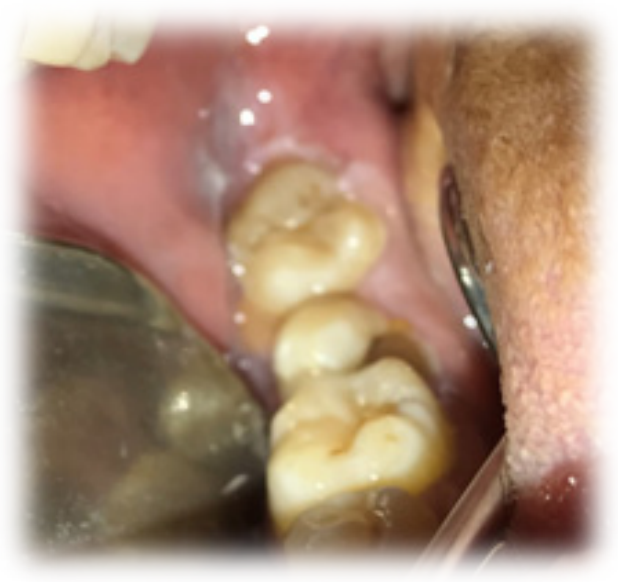

Fig. 3: Intraoral properative view of surgical site

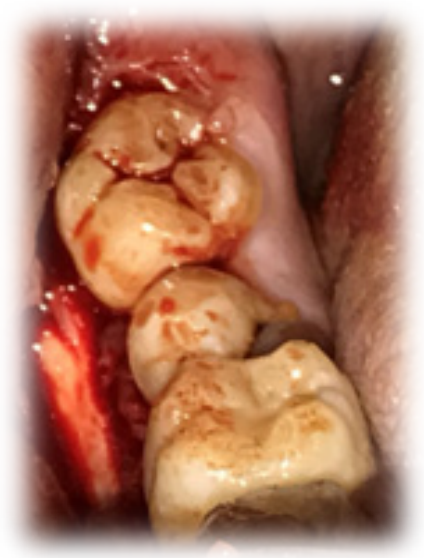

Fig. 4: Flap reflected buccally and retracted using minnesota retractor 


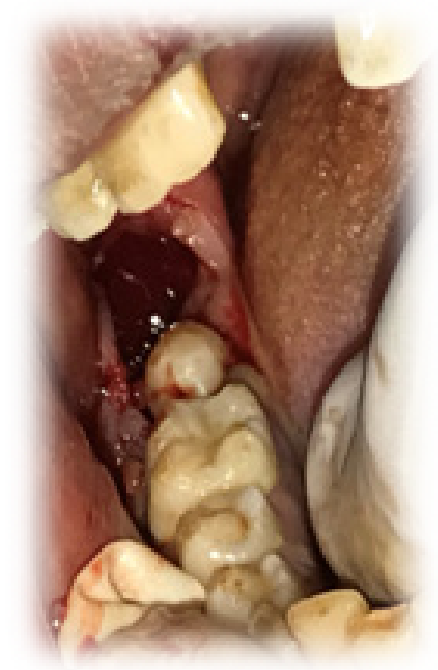

Fig. 5: Surgical site after removal of lower third molar.

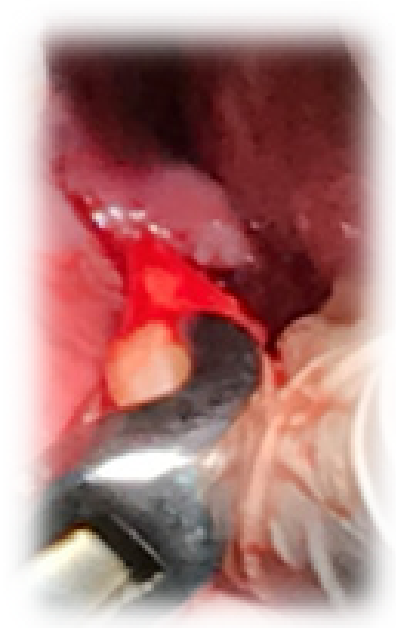

Fig. 6: Delivering of second molar with associated mass using mandibular molar forceps
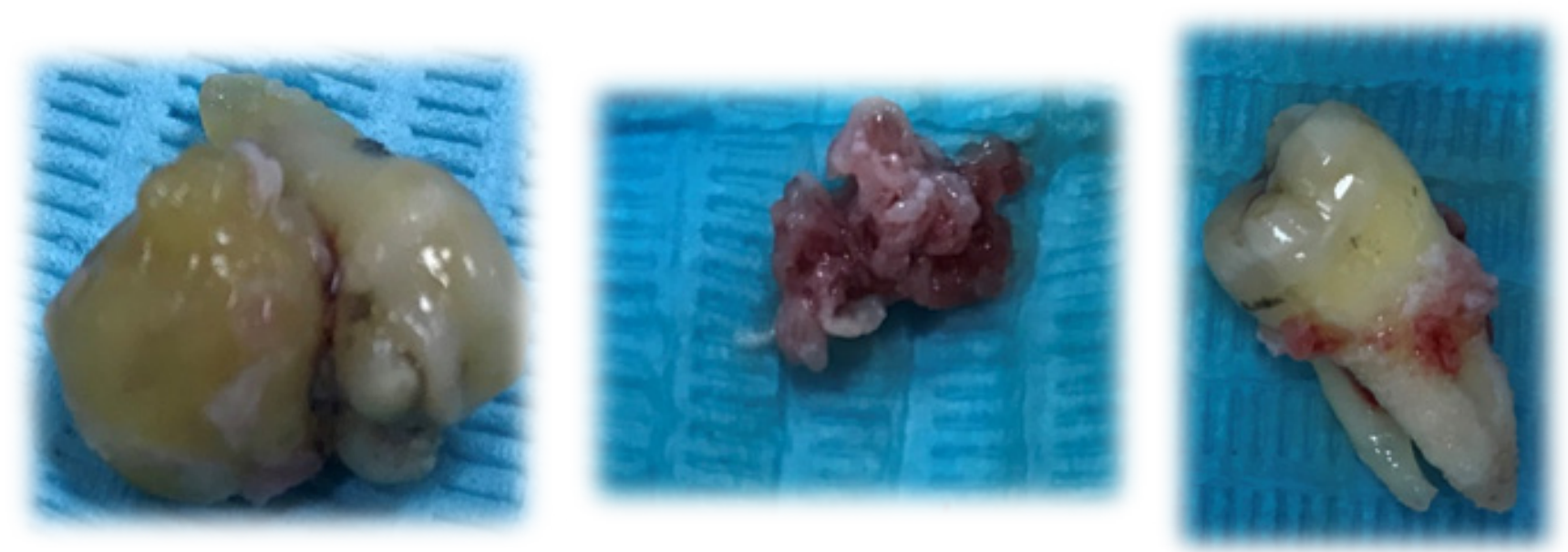

Fig. 7: surgical site after extensive curretage and wound debridment

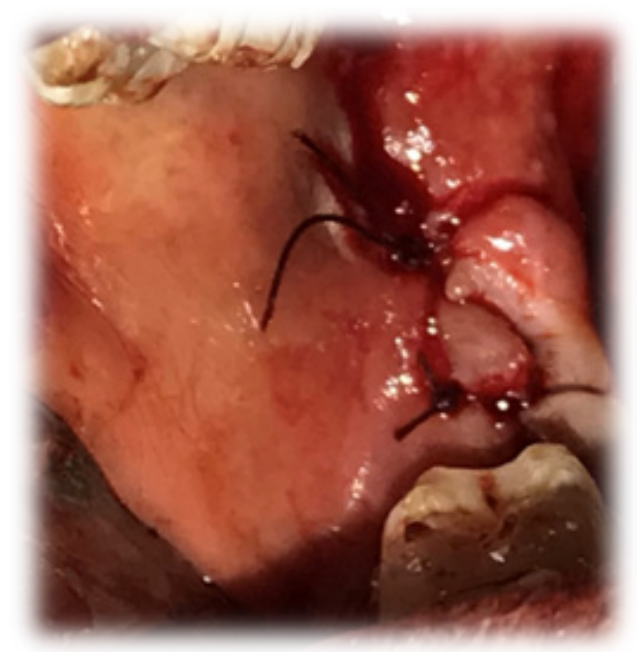

Fig. 8: Suturing of surgical site

Fig. 9a: Mandibular Second right molar with associated mass ; Fig. 9b: Soft tissue curretaged from bony socket of mandibular right second molar ; Fig. 9c: Mandibular right third molar 
Gross examination of the specimen showed a non-carious mandibular molar with the mesial root embedded in a spherical mass of hard tissue. The results of histopathological evaluation revealed proliferating plump cells resembling cementoblasts. In some areas, these cemtoblasts are embeded in variable amounts of eosinophilic matrix (cementoid). In many areas, this cementoid is showing patchy calcifications forming areas of cellular cementum (Figure $10 \mathrm{a}$ and $\mathrm{b}$ ). The definitive diagnosis was true cementoma (benign cementoblastoma).

No complications were recorded postoperatively, and a follow up period of 12 months showed no signs of recurrence (Figure 11 and 12).

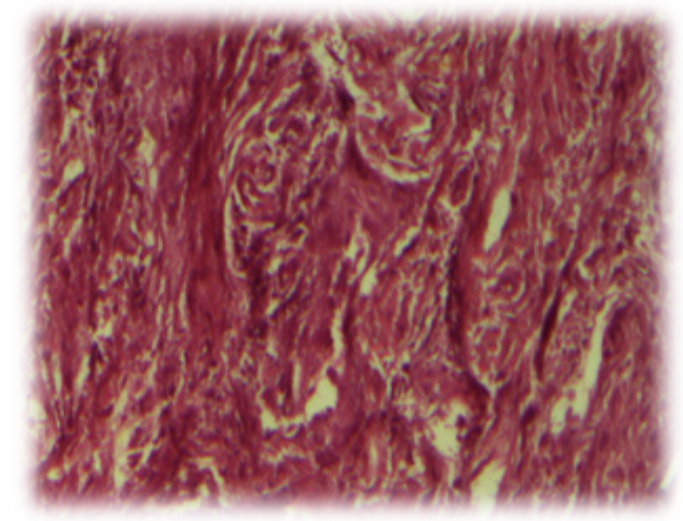

Fig. 10a: H.E. magnification 10x showing calcified tissue with numerous gaps and cemetocytes.

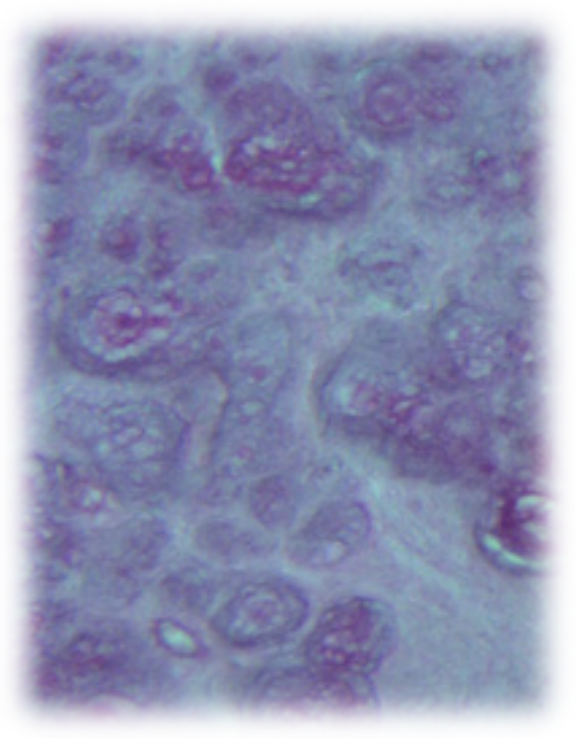

Fig. 10b: H.E. magnification 40x showing plump cells resembling cementoblasts embeded in eosinophilic matrix

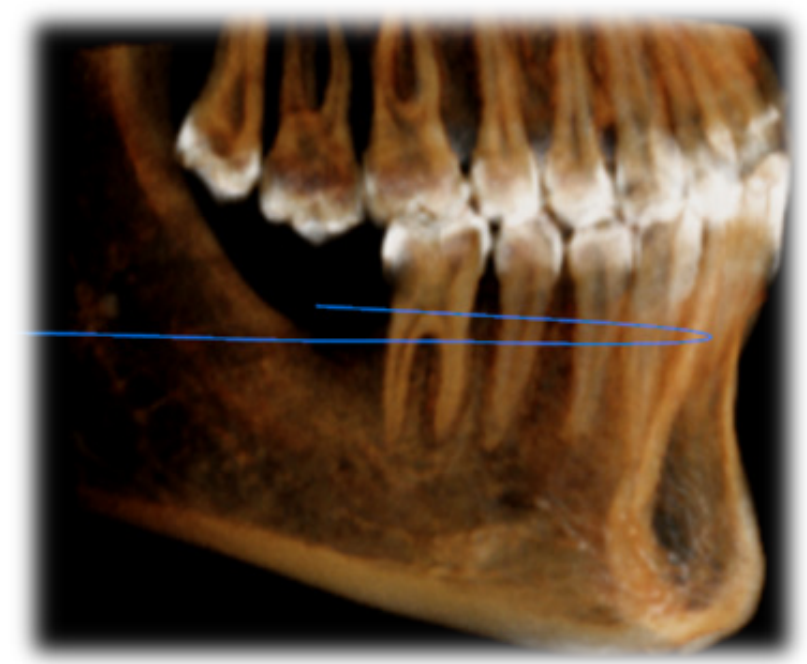

Fig. 11: 3-D reconstruction view of $\mathrm{CBCT}$ showing surgical site 12 months postoperaively withno signs of recurrence

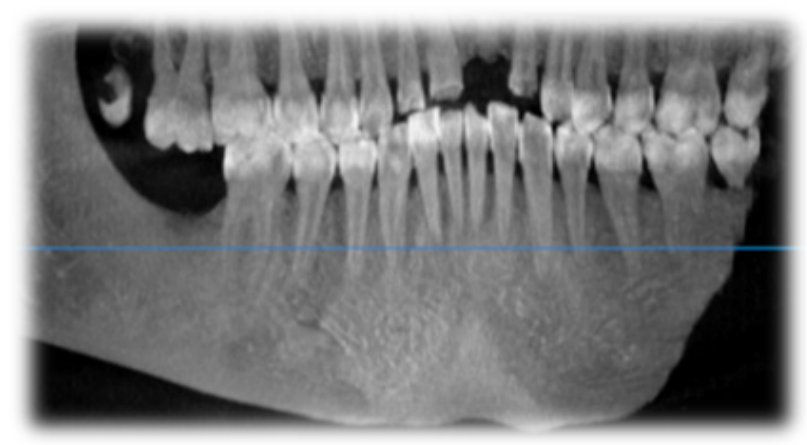

Fig. 12: Reconstructed Panoramic image showing surgical site 12 months postoperaively withno signs of recurrence.

\section{DISCUSSION}

Benign Cementoblastoma is a rare benign mesenchymal odontogenic tumor that was first described by Norberg in $1930^{[1]}$. It is a solitary slowly growing benign tumor, but it was reported that it may exhibit aggressive behavior ${ }^{[19,20]}$ Baart et. al. reported that it has an occurrence rate of less than 1 case per million people per year ${ }^{[14]}$. Pynn et. al. in 2001 stated that there were less than 100 reported cases in literature ${ }^{[21]}$.

Malhotra et. al. concluded that benign cementoblastoma is more common in young male adults ${ }^{[22]}$. Ulmansky et. al. and Berwick et. al. stated that more than half of the patients are less than 20 years and three quarters of them are under the age of $30^{[18,23]}$. Brannon et. al., Ohki et. al. and Zaitoun et. al. also supported that it has a higher prevalence in male patients ${ }^{[7,10,11]}$. 
Benign Cementoblastoma more commonly occur in the mandible (around 70\%) and usually involves premolars or molar roots. According to Malhotra et. al. its most common site is first molar and second premolar ${ }^{[22]}$. When it occurs in the maxilla, it may affect the maxillary sinus as reported by Ohki et al. and Infante-Cossio et al ${ }^{[11,13]}$. It rarely affects multiple teeth, impacted or deciduous teeth. Papageorge et al. in 1987 reported a case involving multiple deciduous teeth ${ }^{[24]}$.Cannell et al. also reported a true cementoma in decdious teeth in 199125 and in 1998 Piattelli et al. reported a benign cementoblastoma related to an impacted third molar ${ }^{[9]}$.

Clinically Milani et al. stated that the lesion may be asymptomatic, but it was reported that benign cementoblastoma can cause pain due to bone expansion, trismus, adjacent tooth mobility and affected tooth displacement ${ }^{[26]}$. True Cementoma has a characteristic radiographic appearance. It presents as a well-defined round radiopaque mass surrounded by a uniform radiolucent rim or halo, which is associated with the root of affected tooth or teeth ${ }^{[27]}$. Root resorption, loss of lamina dura and obliteration of periodontal space have been reported ${ }^{[26]}$.

Histologically, the benign cementoblastoma is characterized by cementum or cementum like tissue, its appearance varies from secondary cellular cementum to gaintcementicles (when deposited in globular pattern $)^{[22]}$. In this case report, H\&E stained section of the specimen showed proliferating plump cells resembling cementoblasts. In some areas, these cemtoblasts are embeded in variable amounts of eosinophilic matrix (cementoid). In many areas, this cementoid is showing patchy calcifications forming areas of cellular cementum. After evaluation of the clinical, radiographical and histopathological findings, the definitive diagnosis of this lesion was benign cementoblastoma (Figure $10 \mathrm{a}$ and $\mathrm{b}$ ).

To reach the definitive diagnosis, the benign cementoblastoma must be differentiated from other periapical radiopaque lesions which include ostoblastoma, osteosarcoma, osteoma, odontoma, periapical cemental dysplasia, condensing osteitis and hypercementosis ${ }^{[21]}$. Pynn et al. summarized the differential diagnosis of those lesions mentioning that although osteoblastoma and cementoblastoma are both histologically similar, cementoblastoma must be related to a root, while osteobastoma occurs in the medulla of the bone and is usually separated from the root by a thin radiolucent line. He added that odontomes are not associated or even related to the roots of teeth and show several dental tissues histologically. While periapical cemental dysplasia shows radiographical variation ranging from radiolucent to radiopaque findings over a period of time. Furthermore, condensing osteitis lacks a well defined radiolucent halo around its lesion differentiating it from benign cementoblastoma. While hypercementosis is an asymptomatic small lesion that does not cause swelling ${ }^{[21]}$.
Due to the location and non-self-limiting nature of the benign cementoblastoma which can lead to the destruction of affected site, treatment is mandatory. The treatment of choice is surgical removal of the tooth or teeth with the associated lesion, wound debridement and extensive curettage of the bony socket and surgical site ${ }^{[6-8,10,14,28,29]}$.

Goerig et al. in 1984 suggested that involved tooth could be salvaged if the lesion is diagnosed early. The tumor is removed surgically by excision, while the tooth undergoes endodontic treatment ${ }^{[28]}$. Hirai et al. in 2009 supported preserving the tooth specially if it is strategic ${ }^{[15]}$. Keyes et al. in 1987 had suggested apicoectomy as a treatment modality (along with excision of the lesion) ${ }^{[29]}$ and was supported by Biggs et al. in 1995, with the condition that after apicoectomy does not compromise the crown root ratio ${ }^{[30]}$.

The prognosis is usually excellent and recurrence of true cementoma is rare following complete excision of the lesion $^{[30]}$.

\section{CONCLUSION}

Benign Cementoblasoma is a rare odontogenic tumor that occur predominately in young male adults. It has unlimited growth potential and therefore the recommended treatment is complete excision with the affected tooth, after the proper diagnostic measures had been undertaken. Recurrence is rare, and the prognosis is excellent.

\section{CONFLICT OF INTEREST}

There are no conflicts of interest.

\section{REFERENCES}

1. Norberg $O$ o. Zurkenntnis der dysontogenetischenGeschwulste der Kieferknochen". Vrtljsschr f Zahnh 1930; 46:321-55.

2. Kramer JR, Pindborg JJ, Shear M. Histological typing of odontogenic tumors, jaw cysts, and allied lesions. In: International histological classification of tumors. Geneva: World Health Organization; 1992. p. 23-40.

3. Hubber, A.R. and Folk, G.S. (2009) Cementoblastoma. Head and Neck Pathol, 3, 133-135. doi:10.1007/s12105-008-0099-5

4. Abrams Am, Kirby JW, Melrose RJ. "Cementoblasotma: a clinical-pathologic study of seven new cases". Oral Surg Oral Med Oral Pathol1974; 38(3):394-403.

5. Cundiff, E.J. (2000) Developing cementoblastoma: 
Case report and update of differential diagnosis. Quintessence International, 31, 191-195.

6. Sumer, M., Gunduz, K., Sumer, P.A. and Gunhan, O. (2006) Benign cementoblastoma: A case report. Medicina Oral, Patología Oral Y Cirugía Bucal, 11, 483-485.

7. Zaitoun, H., Kujan, O. and Sloan, P. (2007) An unusual recurrent cementoblastoma associated with a developing lower second molar tooth: A case report. Journal of Oral and Maxillofacial Surgery, 65, 2080-2082. doi:10.1016/j.joms.2006.06.288.

8. Vieira, A.P.G.F., Meneses, J.M.S. Jr. and Maia, R.L. (2007) Cementoblastoma related to a primary tooth: A case re-port. Journal of Oral Pathology and Medicine, 36, 117-119. doi:10.1111/j.1600-0714.2007.00465.x.

9. Piattelli, A., Di Alberti, L., Scarano, A. and Piatelli, M. (1998) Benign cementoblastoma associated with an unerupted third molar. Oral Oncology, 34, 229-231.

10. Brannon, R.B., Fowler, C.B., Carpenter, W.M. and Corio, R.L. (2002) Cementoblastoma: An innocuous neoplasm? A clinicopathologic study of 44 cases and review of litera-ture with special emphasis on recurrence. Oral Surgery, Oral Medicine, Oral Pathology, Oral Radiology, and En-dodontology, 93, 311-320. doi:10.1067/moe.2002.121993.

11. Ohki, K., Kumamoto, H., Nitta, Y., Nagasaka, H., Kawa-mura, H. and Ooya, K. (2004) Benign cementoblastoma involving multiple maxillary teeth: Report of a case with a review of the literature. Oral Surgery, Oral Medicine, Oral Pathology, Oral Radiology, and Endodontology, 97, 53-58. doi:10.1016/j.tripleo.2003.08.012.

12. Pontes, F.S.C., Carneiro, J.T. Jr., Ribeiro, A.L.R., Gon-çalves, A. Jr., Fonseca, F.P., Pontes, H.A.R. and Pinto, D.S. Jr. (2008) Cementoblastoma previously misdiagnosed as fibrous dysplasia: Report of an uncommon case and dis-cussion of the differential diagnosis. International Journal of Pediatric Otorhinolaryngology Extra, 3, 182-187. doi:10.1016/j.pedex.2008.04.001.

13. Infante-Cossio, P., Hernandez-Guisado, J.M., Acosta-Feria, M. and Carranza-Carranza,A. (2008) Cementoblastomainvolveing the maxillary sinus. British Journal of Oral and Maxillofacial Surgery, 46, 234-236. doi:10.1016/j.bjoms.2007.03.009.
14. Baart, J.A., Lekkas, C. and Van der Waal, I. (1991) Resid-ualcementoblastoma of the mandible. Journal of Oral Pathology and Medicine, 20, 300-302. doi:10.1111/j.1600-0714.1991. tb00932.x.

15. Hirai, E., Yamamoto, K., Kounoe, T., Kondo, Y., Yonemasu, H. and Kurokawa, H. (2010) Benign cementoblastoma of the anterior maxilla. Journal of Oral and Maxillofacial Surgery, 68, 671-674. doi:10.1016/j.joms.2009.03.060.

16. Ackermann GL, Altini M. "Thecementomas - a clinicopathological re-appraisal". J Dent Assoc S Afr. 1992 May; 47(5): 187-94.

17. Mogi K, Belal E, Kano A, Otake K. "Benign cementoblastoma. Case report.” Aust Dent J. 1996 Feb; 41(1):9-11.

18. Ulmanski, M., Hansen, E., Praetorius, F. and Haque, M.F. (1994) Benign Cementoblastoma: A review and five new cases. Oral Surgery, Oral Medicine, Oral Pathology, 77, 48-55. doi:10.1016/ S0030-4220(06)80106-4.

19. Krausen AS, Pullon PA, Gulmen S, Schenck NL, Ogura JH “ Cementomas - aggressive or innocuous neoplasm?" Arch Otolaryngol $1977 ; 103(6): 349-54$

20. Langdon JD. "The benign cementoblastoma - just how benign?" Br J Oral Surg 1976 ;13(3): 239-49.

21. Pynn, B., Sands, T. and Bradley, G. (2001) Benign Cementoblastoma: A Case Report. J Can Dent Assoc, 67:260-2.

22. Malhotra, G., Shukla, P., Dahiya, V., Katraia, P., Joshi, C.S. and Dangi, P. (2015) Cementoblastoma: A case report. Asian Pac. J. Health Sci, 2(4): 101-104.

23. Berwick JE, Maymi GF, Berkland ME "Benign cementoblastoma: a case report" J Oral MaxillofacSurg1990; 48(2): 208-11.

24. Papageorge MB, Cataldo E, Nghiem F. Cementoblastoma involving multiple deciduous teeth. Oral Surg Oral Med Oral Pathol 1987; 63(5):602-5.

25. Cannell H. Cementoblastoma of deciduous tooth. Oral Surg Oral Med Oral Pathol 1991; 71 (5):648.

26. Milani C., Thomé C., Kamikawa R., Silva M. 
and Machado M. Mandibular cementoblastoma: Case report. Open Journal of Stomatology, 2012, 2, 50-53 OJST http://dx.doi.org/10.4236/ ojst.2012.21009.

27. Matteson SR. Benign tumors of the jaws. In: White SC, Pharoah MJ, editors. Oral radiology: principles and interpretation. 4th ed. Toronto: Mosby; 2000. p. 401-2.

28. Goerig AC, Fay JT, King E, « Endodontic treatment of a cementoblastoma » Oral Surg1984; 58(2): 133-6.

29. Keyes G, Hilferbrand $K$ "Successful surgical endodontics for benign cementoblastoma" J Endod 1987; 13(12): 566-9.

30. Biggs, J.T. and Benenati, F.W. (1995) Surgically treating a benign cementoblastoma while retaining the involved tooth. Journal of the American Dental Association, 126, 1288-1290. 